\title{
Crisis Management Modeling of an Economic Object in Conditions Associated with Risks
}

\author{
VITALINA BABENKO ${ }^{1}$, IRINA BABIY², VIKTOR KHELEMSKYI ${ }^{3}$, VIKTORIIA YEVTUSHENKO ${ }^{4}$, \\ TETIANA MANUSHKINA ${ }^{5}$, TETIANA KACHANOVA ${ }^{6}$ \\ ${ }^{1}$ V.N. KARAZIN KHARKIV NATIONAL UNIVERSITY, UKRAINE, E-mail: vitalinababenko@karazin.ua, \\ ORCID: vitalinababenko@karazin.ua \\ ${ }^{2}$ KHMELNYTSKYI NATIONAL UNIVERSITY, UKRAINE, E-mail: irbabiy115@gmail.com \\ ${ }^{3}$ UNIVERSITY OF THE STATE FISCAL SERVICE, UKRAINE, E-mail: vhelemsky@gmail.com \\ ${ }^{4}$ V.N. KARAZIN KHARKIV NATIONAL UNIVERSITY, UKRAINE, E-mail: v.a.evtushenko@karazin.ua \\ ${ }^{5}$ MYKOLAYIV NATIONAL AGRARIAN UNIVERSITY, UKRAINE, E-mail: latushkina2004@gmail.com \\ ${ }^{6}$ MYKOLAYIV NATIONAL AGRARIAN UNIVERSITY, UKRAINE, E-mail: kachanova0909@gmail.com
}

\begin{abstract}
The model of management of an economic object in a crisis is developed. Limitations and quality criteria are formed. General scheme of solving the task of minimax program crisis management at an enterprise is detected. The algorithm of the solution of the problem of crisis management of an enterprise taking into account the risks is offered. The main method for solving the problem is the method of detecting the reachable areas. Using this method, we work out the scenario of optimal crisis management in the presence of risks. The proposed algorithm allows to create effective numerous methods for implementing a computer simulation of solution of the problem of risk's influencing. Simulated tools allow the reducing the risks at information system of crisis management of an enterprise. It opens the perspective of developing computer information systems for support of making effective crisis management decisions in the conditions of uncertainty and lack of information for increasing information security.
\end{abstract}

Keywords: Crises management; Optimal management; Economic object; Program management; Reducing the risks.

JEL Classification: Q26, R13, O15, L83 


\title{
Modelización de la Gestión de Crisis de un Objeto Económico en Condiciones de Riesgo
}

\author{
VITALINA BABENKO ${ }^{1}$, IRINA BABIY², VIKTOR KHELEMSKYI ${ }^{3}$, VIKTORIIA YEVTUSHENKO ${ }^{4}$, \\ TETIANA MANUSHKINA ${ }^{5}$, TETIANA KACHANOVA ${ }^{6}$ \\ ${ }^{1}$ V.N. KARAZIN KHARKIV NATIONAL UNIVERSITY, UKRAINE, E-mail: vitalinababenko@karazin.ua, \\ ORCID: vitalinababenko@karazin.ua \\ ${ }^{2}$ KHMELNYTSKYI NATIONAL UNIVERSITY, UKRAINE, E-mail: irbabiy115@gmail.com \\ ${ }^{3}$ UNIVERSITY OF THE STATE FISCAL SERVICE, UKRAINE, E-mail: vhelemsky@gmail.com \\ ${ }^{4}$ V.N. KARAZIN KHARKIV NATIONAL UNIVERSITY, UKRAINE, E-mail: v.a.evtushenko@karazin.ua \\ ${ }^{5}$ MYKOLAYIV NATIONAL AGRARIAN UNIVERSITY, UKRAINE, E-mail: latushkina2004@gmail.com \\ ${ }^{6}$ MYKOLAYIV NATIONAL AGRARIAN UNIVERSITY, UKRAINE, E-mail: kachanova0909@gmail.com
}

\begin{abstract}
RESUMEN
Se desarrolla el modelo de gestión de un objeto económico en una crisis. Se forman las limitaciones y los criterios de calidad. Se detecta el esquema general de la solución de la tarea de la gestión de crisis del programa minimax en una empresa. Se ofrece el algoritmo de la solución del problema de la gestión de crisis de una empresa teniendo en cuenta los riesgos. El método principal para resolver el problema es el método de detección de las áreas alcanzables. Utilizando este método, se elabora el escenario de la gestión óptima de la crisis en presencia de riesgos. El algoritmo propuesto permite crear numerosos métodos eficaces para implementar una simulación informática de la solución del problema de la influencia de los riesgos. Las herramientas simuladas permiten reducir los riesgos en el sistema de información de la gestión de crisis de una empresa. Esto abre la perspectiva de desarrollar sistemas de información computarizados para apoyar la toma de decisiones efectivas de gestión de crisis en condiciones de incertidumbre y falta de información para aumentar la seguridad de la información.
\end{abstract}

Palabras claves: Gestión de crisis; Gestión óptima; Objeto económico; Gestión de programas; Reducción de riesgos

Clasificación JEL: Q26, R13, O15, L83 


\section{Introduction}

The term "crisis management" in the conditions has not yet been established. The rea-son for the terminological differences is the lack of strong scientific traditions and practical experience in crisis management. The need for crisis management is determined by the objectives of the development of economic systems and the existence of the danger of a crisis (Archibald, 2010 and Alghamdi et al 2018). However, the ambiguity and diversity of the content of the crisis give different reasons for the classification of management in crisis situations (Boehm; Choetkiertikul et.al, 2015).

We will consider the concept of managing an economic object in a crisis as a series of measures to reduce all sorts of risks associated with the development of the studied object or process (Alexander, 2013). Anti-crisis management is a microeconomic category that reflects production relations in relation to a particular enterprise (Esposti and Gomez, 2015). At the enterprise level, they are formed as a combination of forms and methods for implementing anti-crisis procedures. Economic activity this is all kinds of activities of people that allow society to supply themselves with material resources for existence (Machac and Steiner, 2014). The set of problems associated with the life of the enterprise in a crisis, leads to various types of risks (Halynska and Oliinyk, 2020, Hrabovskyi et al., 2020), An effective solution to these problems is carried out on the basis of solving the problem of optimizing the management of an economic object (enterprise) in the presence of risks (Kumar and Yadav, 2015).

An analysis of literature on modeling in crisis management of an economic objects in a crisis has shown that there are difficulties associated with the dynamics of a model [19]. This is due to the parameters changing over time, as well as to complexity of the nature of relationship between the components of the model (including existence of delays and "feedback") (Kuprina et. al, 2019).

\section{Literature review}

Realization of the problems, associated with modeling of crisis management in practice contributed to scientific development and widespread application of hybrid models based on a combination of formal and informal text, verbal and special graphic approaches (Vasylieva, 2019). These tools offer simplified models and in many cases involve graphic interpretation of (Danchenko, 2014). As a result, most models of crisis management were implemented by descriptive means or represented fragmentarily, with insufficient analytical formalization (Skopenko et.at, 2013, Bhatti et al 2018). Some of them are characterized by lack of practical focus, integrity, and complexity in crisis management (Rishnyak, 2011, Boehm, 2020), they simplify obtaining knowledge and offer opportunity to experiment with crisis management. In this case, there is no possibility to assess the impact and consequences of different variants for crisis management in the prospects of minimization of risks of crisis while making managerial decisions (Bossu et al., 2018, Malyarets et.al, 2019). Thus, crisis management with the use of simulation remains an unresolved problem for researchers (Podgorna et. al,2020). In addition, existing models may have a limited availability and must be adapted to conditions of activity of specific enterprises (Zhuravlyov et al., 2018, Babenko et.al, 2021).

The problem of modelling of crisis management was most fundamentally studied in. The general problems of risk's reduction at an enterprise's crisis management sys-tem were examined, which have a common effect on the functionality of the enterprise and in critical infrastructures as a whole (saeed et al 2019).

\section{Model of Crisis Management of an Economic Object on Example of an Enterprise}

\subsection{Structural and functional model of solving the task of dynamic optimization of the program crisis management of an enterprises in conditions associated with risks}

Consider the current economic and mathematical model of crisis management at an enterprises (CME) associated with risks. On a given integer time interval $\overline{0, T}=\{0,1, \mathrm{~K}, T\}(T>0)$ we consider multistage dynamic management system of innovative process (IP), which consists of a single 
management object (enterprise for processing agricultural raw materials), the movement of which is described by a linear discrete recurrent vector equation (dynamic model) (Boehm, 2020). Here and further for simplification of mathematical calculations we will consider the following equation:

$$
\begin{gathered}
x(t+1)=A(t) x(t)+B(t) u(t)+C(t) v(t), \\
x(0)=\left\{x_{0}, I_{0}\right\}
\end{gathered}
$$

where $t \in \overline{0, T-1}=\{0,1,2, \ldots, T-1\}$ - the discrete moments of time, divided by a period of a month, quarter, year in which the choice of management; - a given period of time ( $T>0$ and integer);

$\bar{x}(t+1) \in \mathbf{R}^{\bar{n}}$ - the phase vector characterizing the state of management of SP in the period of time $(t+1)$ and consists of vectors of volumes of production, production stocks, expenses, financial resources and volumes of investments which were formed of the period of time $(t+1)$ (stocks in the period $(t+1)$ ).

Lets consider the formation (1) on the example of the vector production volumes of the enterprise: $\mathrm{xi}(\mathrm{t}+1)$ the number of $\mathrm{i}$-th type of products $i \in \overline{1, n}$ formed in the warehouse prior to the beginning of the time period $(t+1)$ (inventory of products in the period $(t+1)$ ), which is formed from stocks $x i(t)$ of the previous time period and the products produced at the enterprise for the time period $t$.

Equation (1) consists of three components: the remains of unrealized products for the period, manufactured products in the period and the impact of risks for the study period of time.

components, which we consider below (the remains of unrealized products for the period, manufactured products in the period and the impact of risks for the study period of time).

- The remnants of unsold goods in period $t+1$.

Note that if at the beginning of the time period $t$ there were stocks in the amount of $x(t)$, then by the end of this period, that is, by the beginning of the time period $t+1$, only a part equal to $A(t) \bar{x}(t)$;

- $A(t)=\left\|a_{i i}(t)\right\|_{i \in \overline{1, n}}$ diagonal matrix characterizing the sales of products (matrix of "sales") over a period of time ;

$\bar{x}(t)=\left(x_{1}(t), x_{2}(t), \mathrm{K}, x_{n}(t)\right)^{\prime} \in \mathbf{R}^{n}$ - the vector of stocks of production in the period $\mathrm{t}$ ( $t \in \overline{0, T-1})$ in which each $\mathrm{i}$ and coordinate

$\mathrm{xi}(\mathrm{t})$ designates volume of production of the i-th type $i \in \overline{1, n}$ (n - total number of types of products), $\quad \mathbf{R}^{n}-\mathrm{n}$-dimensional vector space of vectors columns.

- Manufactured products in period $\mathrm{t}+1$ (vector $B(t) \bar{u}(t))$ ),

where $\bar{u}(t) \in \mathbf{R}^{p}$ - is the vector of management of IP (control action), the components of which are the intensities the use of the j-th technological method of production of products (according to the corresponding $(\mathbb{P}$ ) in the time period $\mathrm{t}, p \in \mathbf{N}$ in which each $\mathrm{j}$-th coordinate is the value of the volume production of material and labor resources and investments for SP, $(j \in \overline{1, \bar{n}}), \forall t \in \overline{0, T-1}$ $\bar{u}(t) \in U_{1}, U_{1}$ - a finite set of alternatives, which limits the resource management impact;

$$
B(t)=\left\|b_{i j}(t)\right\|_{i \in \overline{1, n}, j \in \overline{1, p}} \text { - "technological matrix" of production, the components of which can be }
$$
represented by the $\mathrm{j}$-th way, which corresponds to the organization of production $(j \in \overline{1, p}=\{1,2, \mathrm{~K}, p\})$ in the time period $\mathrm{t}(t \in \overline{0, T-1}, T>0)$, which is characterized by the vector $(b 1 j(t), b 2 j(t), \ldots, b n j(t))$ norms of expenses of resources for the manufacture of a unit volume production of the $\mathrm{i}$-th species $(i \in \overline{1, n})$. If $\mathrm{bij}(\mathrm{t})<0$, the value $\mathrm{bij}(\mathrm{t})$ determines the cost of the $\mathrm{I}$-th ingredient $i \in \overline{1, n}$ during the $\mathrm{j}$-th mode of production in the time period. 
A term that takes into account the impact of risks, modeling errors on products in the period $\mathrm{t}+1$ (vector $C(t) \bar{v}(t)$, where $\bar{v}(t) \in \mathbf{R}^{q}$ - risk vector, which affects the production and storage of products, that is, the process of vector formation $\bar{x}(t+1) q \in \mathbf{N}$. For example, investment payments (or their shortfall), short supply of components, spoilage agricultural products during storage or transportation, non - compliance with the quality requirements of raw materials or finished products, insufficient investment, etc.;

$$
\begin{aligned}
& \forall t \in \overline{0, T-1} \bar{v}(t) \in V_{1} \text { - convex, closed and limited polyhedron in } \mathbf{R}^{q} \\
& C(t)=\left\|c_{i l}(t)\right\|_{i \in \overline{1, n}, l \in \overline{1, q}} \text { - a matrix consisting of coefficients listing the impact of the risk vector }
\end{aligned}
$$
on the products of each type.

$A(t), B(t), C(t)$ - matrices of dimensions $\left(n^{*} n\right),\left(n^{*} p\right)$ and $\left(n^{*} q\right)$ respectively, formed on the basis of preliminary information from the enterprise reporting documents, available statistical data on the considered the process, with the help of experts, economic forecasts and other sources through the use of data evaluation methods and solving a separate problem of identification of the parameters of the system under study (Sviridova , 2011, Gontareva et al., 2020).

Formation of restrictions for the process management of IP processing APK enterprises. Introduced above he controls vector of IP and the risk vector $\bar{u}(t)=\left(u_{1}(t), u_{2}(t), \mathrm{K}, u_{p}(t)\right)^{\prime} \in \mathbf{R}^{p}$ in the system (3.1) such that each pair $(\bar{u}(t) \bar{v}(t))$ must satisfy such a given restriction:

$$
\begin{gathered}
(\bar{u}(t), \bar{v}(t)) \in U V(t)=\left\{(\bar{u}(t), \bar{v}(t)): \bar{u}(t) \in \mathbf{R}^{p}, \bar{v}(t) \in \mathbf{R}^{q},\right. \\
\left.S_{\text {min }}(t) \leq\langle B(t) \bar{u}(t)\rangle_{n} \leq S_{\text {max }}(t), K_{\text {min }}(t) \leq\langle C(t) \bar{v}(t)\rangle_{n} \leq K_{\text {max }}(t)\right\},
\end{gathered}
$$

Where $S_{\min }(t)=\left(S_{\min 1}(t), S_{\min 2}(t), \ldots, S_{\min n}(t)\right)^{\prime} \in \mathbf{R}^{n}$

the vector of the minimum acceptable volume of production, in which each I-coordinate $S_{\min i}(t)$ is the value of the minimum acceptable volume of production of the l-th type $(i \in \overline{1, n}$ ) (for example, the break-even point for each type of product);

$$
S_{\max }(t)=\left(S_{\max 1}(t), S_{\max 2}(t), \ldots, S_{\max n}(t)\right) \in \mathbf{R}^{n}
$$

vector of the upper limit output, in which each I-coordinate is the value of the maximum acceptable volume of production of the I-th type $(i \in \overline{1, n})$ (for example, the maximum market capacity for each product name, the maximum production capacity, etc.).). $K_{\min }(t)=\left(K_{\min 1}(t), K_{\min 2}(t), \ldots, K_{\min n}(t)\right)$ and $K_{\max }(t)=\left(K_{\max 1}(t), K_{\max 2}(t), \ldots, K_{\max n}(t)\right)-$ the influence of the risk vector on the output of each type of product [63].

The following constraints $t \in \overline{0, T-1}$ must also be met for all:

$$
\begin{cases}x_{i}(t) \geq 0 & (i \in \overline{1, n}) \\ u_{j}(t) \geq 0 & (j \in \overline{1, p}) \\ v_{l}(t) \geq 0 & (l \in \overline{1, q})\end{cases}
$$

It should be noted that in the process management of the enterprise's sole proprietorship of restrictions (2), (3) is a necessary condition that must satisfy the parameters of the system states generated by the implementation of optimal management actions in a discrete dynamic system (1).

Formation of quality criteria for assessing the implementation other management process of IP processing APK. The quality of the system control process (1) on the integer time interval $\overline{0, T}$, in particular, is estimated by the functional, the value $\Phi(u(\cdot))$, which for the fixed control of the IP is calculated by the formula: 


$$
\begin{gathered}
\Phi(u(\cdot))=\max _{v(\cdot) \in V(\overline{0, T})} \gamma\left(x_{\overline{0, T}}\left(T ; x_{0}, I_{0}, u(\cdot), v(\cdot)\right)=\right. \\
=\max _{x(T) \in G_{\overline{0, T}}^{+}\left(T ; x_{0}, I_{0}, u(\cdot), V(0, T)\right)} \gamma(x(T)),
\end{gathered}
$$

where $\gamma: \mathbf{R}^{n} \rightarrow \mathbf{R}^{1}$ is a functional defined on the final vectors of the system state (1), which evaluates the quality of IP management.

It is advisable to consider the following specific types of functionality:

1) $\gamma(x(T))$ is a linear function $\forall x \in \mathbf{R}^{n}$ that is the role of the optimization criterion we use the linear functional;

2) $\gamma(x(T))$ - convex function, that is, we use convex functional.

Consider the first case when is a linear function $\forall x \in \mathbf{R}^{n}$.

For example, $\gamma(x(T))=\left\langle c, x(T)>_{n} \quad\right.$ a scalar product of a vector $x(t) \in \mathbf{R}^{n}$ corresponding to a fixed vector. Then, if the vector of prices for products of a single volume $c(t)=\left\{c_{1}(t), c_{2}(t), \mathrm{K}, c_{n}(t)\right\} \in \mathbf{R}^{n} \quad$ (unit of production) of each type is taken as a vector, then the optimization criterion will be the volume of gross profit from the sale products of the enterprise in the period of time $\mathrm{t}(t \in \overline{0, T-1})$.

Consider the case when $\gamma(x(T))$-convex real function $\forall x \in \mathbf{R}^{n}$. This case should be considered in planning tasks, when a fixed order for the volume of production is set, and it is necessary to "approach" as much as possible to the specified volume. In this case, consider the distance from the possible final phase vector of the system to a given fixed vector in space $\mathbf{R}^{n}$ as a functional value (we perform the operation of calculating the Euclidean norm between these vectors in space $\mathbf{R}^{n}$ ), which is a convex function.

Statement of the problem optimization program management of IP of the processing APK enterprises.

Adoption process in conditions of uncertainty of economic conditions and environment, as well as the resulting risk leads to the need solving the problem of the best choice in terms of incomplete information about the system under consideration. A typical situation associated with decision-making in dynamic systems is the need to organize the procedure of program management in conditions of uncertainty and the resulting risk. Such a procedure, aimed at achieving a particular management goal, is often necessary to accompany the optimization process, allowing to obtain a guaranteed, better or acceptable in some sense result, that is, to use a minimax approach [22].

Let us consider a variety of alternatives to possible management actions:

$$
U(\overline{0, T})=\left\{u(\cdot): u(\cdot)=\{u(t)\}_{t \in \overline{0}, T-1}, \forall t \in \overline{0, T-1}, u(t) \in U_{1}\right\}
$$

there is a set of all possible program managements of IP on a period of time $\overline{0, T}$,

$$
V(\overline{0, T})=\left\{v(\cdot): v(\cdot)=\{v(t)\}_{t \in \overline{0, T-1}}, \forall t \in \overline{0, T-1}, v(t) \in V_{1}\right\}
$$

is the set of all valid implementations risk in the interval $\overline{0, T}$.

On the basis of the provisions of the formulated concept, to solve the optimization problem of IP management, for each fixed program management, we construct an appropriate area of reach, which is determined by sorting out all possible acceptable risk vectors [81]. The convex hull of each constructed reachability domain is a convex polyhedron (since they were defined for vectors that are 
vertices polyhedral constraints) [356], at the vertices of which the functions are optimized to take extreme values. For each domain of reach (corresponding polyhedron), we find a vertex (vector) that determines the maximum value of the objective function for the corresponding fixed program control and the available implementations of the risk vectors, which is generated by the corresponding worst implementation of this vector. Further, from this set of sets and possible program controls and the corresponding maximum values of the objective function, we choose such a pair that the maximum value of the objective function is the smallest (minimum) that is the guaranteed value of the objective function or minimax result. The software control included in this pair satisfies the minimax condition, that is, it is a minimax control of the IP, or guaranteed control of the IP.

Note that the minimax condition (principle) is applied in problems of canonical form when we investigate the target function for the minimum. In the real practical formulation of the problem of optimization management of IP there can be a situation when it is necessary to maximize the target function, that is to solve the problem on Maximin (in this case, the worst risk vectors and minimize the target function). In order to bring such a problem to the minimax problem, it is necessary to turn the original target function into the opposite one by multiplying its values by $(-1)$, thus forming a new target function. Then it is known that minimax control will coincide with Maximin, therefore, it is sufficient to investigate only minimax problems.

For fixed possible implementations of program control of IP $u(\cdot) \in U(\overline{0, T})$ and risk vector $v(\cdot) \in V(\overline{0, T})$, consider $x_{\overline{0, T}}\left(T ; x_{0}, I_{0}, u(\cdot), v(\cdot)\right)$ - the final state (state at time $\mathrm{T}$ ) of the process trajectory generated by the system (3.1) [323] corresponding to the pair $(u(\cdot), v(\cdot))$. Develop plurality:

$$
\begin{gathered}
G_{\overline{0, T}}^{+}\left(T ; x_{0}, I_{0}, u(\cdot), V(0, T)\right)=\left\{x(T): x(T) \in \mathbf{R}^{n},\right. \\
\left.\quad x(T)=x_{\overline{0, T}}\left(T ; x_{0}, I_{0}, u(\cdot), v(\cdot)\right), v(\cdot) \in V(0, T)\right\}
\end{gathered}
$$

- the reachability range [355] of the system (3.1), that is the set of all possible final States of this system at the initial $x(0)=\left\{x_{0}, l_{0}\right\}$ which corresponds to the fixed program control of the IP $u(\cdot) \in U(\overline{0, T})$.

The quality of the system management process (3.1) on an integer period of time $\overline{0, T}$ is estimated by the functional $\Phi(u(\cdot))$, the value of which for the fixed program control of the IP and the initial state of the process

$x(0)=\left\{x_{0}, I_{0}\right\}$ calculate by the formula:

$$
\begin{aligned}
\Phi(u(\cdot))= & \max _{v(\cdot) \in V(\overline{0, T})} \gamma\left(x_{\overline{0, T}}\left(T ; x_{0}, I_{0}, u(\cdot), v(\cdot)\right)=\right. \\
= & x(T) \in G_{\overline{0, T}}^{+}\left(T ; x_{0}, I_{0}, u(\cdot), V(0, T)\right)
\end{aligned}
$$

where $\gamma: \mathbf{R}^{n} \rightarrow \mathbf{R}^{1}$ is the functional defined on the final phase vectors of the equation (3.1), which evaluates the quality of IP.

Then we can formulate the problem of software minimax IP control: you need to find the optimal minimax software IP control, satisfies the condition (minimax):

$$
\begin{aligned}
& \Phi^{(e)}=\Phi\left(u^{(e)}(\cdot)\right)=\max _{v(\cdot) \in V(\overline{0, T})} \gamma\left(x_{\overline{0, T}}\left(T ; x_{0}, I_{0}, u^{(e)}(\cdot), v(\cdot)\right)=\right. \\
& =\min _{u(\cdot) \in U(\overline{0, T)}} \max _{v(\cdot) \in V(\overline{0, T})} \gamma\left(x_{\overline{0, T}}\left(T ; x_{0}, I_{0}, u(\cdot), v(\cdot)\right)=\right. \\
& =\max _{x(T) \in G_{\overline{0} T}^{+}\left(T ; x_{0}, I_{0}, u^{(e)}(\cdot), V(0, T)\right)} \gamma(x(T))= \\
& =\min _{u(\cdot) \in U(\overline{0}, T)} \max _{x(T) \in G_{\overline{0}, T}^{+}\left(T ; x_{0}, I_{0}, u(\cdot), V(0, T)\right)} \gamma(x(T)),
\end{aligned}
$$


where $\Phi^{(e)}=\Phi\left(u^{(e)}(\cdot)\right)$ - is the minimax result of solving this problem (Esposti and Gomez, 2015).

Thus, the formed relations (1-7) are the economic-mathematical model of the problem formulated above.

It should be noted that this system allows to simulate the dynamics of a multi-step process of UIPP APK depending on the given initial conditions and the choice of specific implementations of management actions.

\section{The Algorithm of the Solution of the Problem of Crisis Management at an Enterprise Taking into Account the Risks}

1. Form the set of alternatives of possible crisis management. The components of the first group of control vectors from this set represent the volumes of production of new products over a period of time (according to the corresponding process) (the first level of management).

2. Based on the values of the first group of crisis management vectors, we build a plurality of material, labor and investment resources (second level of management).

3. Determine the set of permissible risks with appropriate constraints.

4. We consistently capture the crisis management with the corresponding vector of replenishment of material and labor resources, investment resources and "take away" all the risks from the set of permissible. We construct the corresponding predictable sets of reach regions $G$ for the final vectors $x(T)$ of the crisis management state at the moment $T$.

5. On the sets of reach domains, we solve the discrete optimization problem with the help of minimax and find the rational program control, which provides a guar-anteed result of the solution of the $\mathrm{CME}$ problem under the influence of any risks from the set of permissible.

\section{Conclusion}

Thus, for organization of minimax crisis management at an enterprise in the selected class of permissible strategies for adaptive management, the model of adaptive management was developed. The proposed recurrent algorithm reduces an original multi-step problem to implementation of the ultimate sequence of problems of minimax soft-ware crisis management at an enterprise. In turn, solution of each of these problems is reduced to implementation of the finite sequence of only onestep optimization operations in the form of solutions of linear and convex mathematical programming and discrete optimization. Then it is possible to obtain a solution of the considered model of adaptive crisis management at an enterprise in the face of risks. Solution is reduced to implementation of solution of a finite sequence of problems of linear convex mathematical programming and discrete optimization.

Presented results can be used for economic-mathematical modeling and solution of other problems of management processes optimization. Economic-mathematical models for such problems are presented, for example, in papers (Kumar and Yadav, 2015; Machac and Steiner, 2014; Schwalbe, 2012; Teslenko, 2010). Prospects of the conducted research are associated with possibility of introduction of parameters of the vector of non-determined risks into a model of crisis management at an enterprise.

The developed models are an effective tool of modeling of optimization of the guar-anteed outcome of crisis management associated with risk factors for enterprises. The results obtained can be used for economic-mathematical modeling and solution of other problems of optimization of processes of data forecasting and management. This takes into consideration conditions of information deficit and uncertainty in the face of risks. The developed mathematical apparatus can be used for implementation of the relevant program-technical complexes for supporting effective managerial decision making in practice. 
Developed tools of modeling in crisis management at an enterprise make it possible to solve the problems of reducing the risks of management of processes at an enterprise.

\section{References}

1. Alexander, D. Social media in disaster risk reduction and crisis management. Science and Engineering Ethics, 20(3), 2013, 717-733,

2. Alghamdi, A., \& Akbar, M. K. (2018). Implementation of an Implicit Solver in ADCIRC Storm Surge Model. Journal of Marine Science and Engineering, 6(2), 62.

3. Archibald, R. Managing High-Tech Programs and Projects. Trans. with English, 3rd ed., revised. and ext. ITT Company; DMK Press, Moskow, 2010.

4. Babenko, V., Perevozova, I., Kravchenko, M., Krutko, M., and Babenko, D. Modern processes of regional economic integration of Ukraine in the context of sustainable development. E3S Web Conf., 166, 2020, 12001. https://doi.org/10.1051/e3sconf/202016612001

5. Babenko, V., Panchyshyn, A., Zomchak, L., Nehrey, M., Artym-Drohomyretska, Z., Lahotskyi, T. Classical Machine Learning Methods in Economics Research: Macro and Micro Level Example. WSEAS Transactions on Business and Economics, Vol. 18, Art. \#22, 2021, pp. 209-217. https://doi.org/10.37394/23207.2021.18.22

6. Bossu, R., Roussel, F., Fallou, L., Landès, L., Steed, R., Mazet-Roux, G., ... Petersen, L. Last Quake. From rapid information to global seismic risk reduction. International Journal of Disaster Risk Reduction, 28, 2018, 32-42. https://doi.org/10.1016/j.ijdrr.2018.02.024

7. Boehm, B.A. Prioritized Top-Ten List of Software Risk Items. Access mode: http://users.humboldt.edu/smtuttle/s12cs435/435lect06-2/435lect06-2-boehm-top10-risks-to-post.pdf (last access: 22.11.2020).

8. Choetkiertikul, M., Dam, H.K., Tran, T. Predicting Delays in Software Projects Using Net-worked Classification (T). Automated Software Engineering (ASE), 30th IEEE/ACM International Conference, 2015, 353-364.

9. Danchenko, A.B. Modern approaches to deviation management in projects. Management of complex systems development, 2014, 19.

10.Degli Esposti, S., \& Santiago Gomez, E. Acceptable surveillance-orientated security technologies: Insights from the SurPRISE project. Surveillance \& Society, 13(3/4), 2015, 437-454.

11.Gontareva, I., Babenko, V., Yevtushenko, V., Voloshko, N., \& Oliynyk, Y. Efficiency of Information Management and Analysis for Industrial Entrepreneurship. Journal of Information Technology Management, 12(3), 2020, 4-13. ttps://doi.org/110.22059/jitm.2020.76288

12.Zhuravlyov, V.; Varkova, N.; Aliukov, S.; Khudyakova, T. Strategic Aspects of Ensuring Sustainable Development of Gold Enterprises of the Russian Federation. Sustainability, 10, 2018, 4410. https://doi.org/10.3390/su10124410

13. Halynska, Y., Oliinyk, V. Modeling of the Distribution Mechanism for Fuel Industry Enterprises' Rental Income in the System. State - Region - Enterprise. Journal of Advanced Research in Law and Economics, Vol. 11, 2(48), 2020, pp. 370-381. https://doi.org/10.14505/jarle.v11.2(48).10

14.Hrabovskyi, Y., Babenko, V., Al'boschiy, O., Gerasimenko, V. Development of a Technology for Automation of Work with Sources of Information on the Internet. WSEAS Transactions on Business and Economics, 17(25), 2020, 231-240. https://doi.org/10.37394/23207.2020.17.25

15.Kumar, C., Yadav, D. K. A probabilistic software risk assessment and estimation model for software projects. Procedia Computer Science, 54, 2015, 335-361.

16.Kuprina N., Stupnytska T., Vaskovska K., Boyko O., Baraniuk Kh., \& Markova T. Manag-ing the competitiveness of the enterprise in the context of transformational change. Interna-tional Journal of Recent Technology and Engineering, 8(2), 2019, 4909-4914. https://doi.org/10.35940/ijrte.B3706.078219

17.Malyarets, L.M., Babenko, V.O., Nazarenko, O.V., Ryzhikova, N.I. The Modeling of Multi-criteria Assessment Activity in Enterprise Management, Int. J Sup. Chain. Mgt, 8, 4, 2019, 997-1004. URL: http://ojs.excelingtech.co.uk/index.php/IJSCM/article/view/3342 
18.Nehrey, M., Kaminskyi, A., \& Komar, M. Agro-economic models: a review and directions for research. Periodicals of Engineering and Natural Sciences, 7(2), 2019, 702-711.

19. Machac, J., Steiner, F. Risk Management in Early Product Lifecycle Phases. International Review of Management and Business Research, 2(3), 2014, 1151-1162.

20.Oliinyk, V., Wiebe, I., Syniavska O., Yatsenko, V. Optimization model of Bass. Journal of Applied Economic Sciences. Volume XIII, Winter, 8(62), 2018, 2168- 2183.

21.Podgorna, I., Babenko, V., Honcharenko, N., Sáez-Fernández, F. J., Fernández, J. A. S., Yakubovskiy, S.. Modelling and Analysis of Socio-Economic Development of the European Union Countries through DP2 Method. WSEAS Transactions on Business and Economics, Volume 17, 2020, Art. \#44, pp. 454-466. https://doi.org/10.37394/23207.2020.17.44

22.Rishnyak, I.V. Risk management system for IT projects. Information Systems and Net-works. Collection of Scientific Papers, Publisher of Lviv Polytechnic National University, Lviv, 2011, 250259.

23.Saeed, S., Nizamani, M. A., Shaikh, A., Memon, M. A., Abbasi, F. A., \& Naqvi, S. M. R. (2019). Evaluating the Quality of Point of Sale (POS) Software. University of Sindh Journal of Information and Communication Technology, 3(2), 69-75.

24.Schwalbe, K.: Information technology project management. Cengage Learning, 2012.

25.Skopenko, N.S., Evseeva, I.V., Moskalenko, V.O. Risk management in project management. Investments: practice and experience, 24, 2013, 41-44.

26.Sviridova, S.S. Risk Management of the Innovation Project Lifecycle. Economics: Realities of Time, 1, 2011, 103-108.

27.Teslenko, P.A. Evolutionary theory and synergetics in project management. Project man-agement and production development, 2010, 4(36).

28.Vasylieva, N. Problems and Prospects of Food Security in Ukraine. Bulgarian Journal of Agricultural Science, 25(4), 2019, 668-676. 